\title{
Employees' Involuntary Non-Use of ICT Influenced by Power Differences: A Case Study with the Grounded Theory Approach
}

\author{
Thale Kvernberg Andersen \\ SINTEF Technology and Society and \\ Norwegian University of Science and Technology, \\ Trondheim, Norway \\ thale.k.andersen@sintef.no
}

\begin{abstract}
Power differences affect implementation of information and communication technology (ICT) in a way that creates differences in ICT use. Involuntary non-use of new ICT at work occurs when employees want to use the new technology, but are unable to due to factors beyond their control. Findings from an in-depth qualitative study show how involuntary non-use of new ICT can be attributed to power differences between occupational groups in the same organization. The findings suggest that experience is a moderating variable and that closeness to formal power holders as well as closeness to the new technology increases the probability for expert control of the ICTorganization processes. These power differences favor ICT experts over ICT novices and result in a high-quality learning environment for the ICT experts characterized by autonomy, inclusion, and adequate work processes and technological solutions. The ICT novices try to navigate in a learning-hostile work environment characterized by marginalization through expert control, isolation, and inadequate work processes and technological solutions. This led to involuntary non-use by the ICT novices, while the experts became more proficient in ICT use. These findings give managers facing a technological organizational change tools to understand important mechanisms for implementing the change in their own organization, and help them take the right actions to integrate new technology and new organization of work.
\end{abstract}

Keywords: ICT implementation, power, organizational change, involuntary non-use, working conditions, learning, ICT resistance

\section{Introduction}

ICT's ability to affect organizational roles, structures, and the organization of work creates a complex relationship between technolo-

Material published as part of this publication, either on-line or in print, is copyrighted by the Informing Science Institute. Permission to make digital or paper copy of part or all of these works for personal or classroom use is granted without fee provided that the copies are not made or distributed for profit or commercial advantage AND that copies 1) bear this notice in full and 2) give the full citation on the first page. It is permissible to abstract these works so long as credit is given. To copy in all other cases or to republish or to post on a server or to redistribute to lists requires specific permission and payment of a fee. Contact Publisher@InformingScience.org to request redistribution permission. gy and organization (Constantinides \& Barrett, 2006; Leonardi \& Bailey, 2008; Zuboff, 1988). Research has explored factors that facilitate the acceptance and use of new ICT (Beaudry \& Pinsonneault, 2010; Legris, Ingham, \& Collerette, 2003), causes of resistance towards using new ICT (Jian, 2007; Martinko, Gundlach, \& Douglas, 2002), barriers to ICT use (Venkatesh, Bala, \& Sykes,

Editor: Geoffrey Z. Liu

Submitted: April 3, 2015; Revised: June 30, 2015; Accepted: July 13, 2015 
2010), as well as power relations and political processes (Boonstra \& Bennebroek Gravenhorst, 1998; Thompson, 2005). The nature of non-use is understudied, and in general it is presumed to be resistance. The study of individual experiences, cognitions, and behaviors dominate the field, at the expense of dynamic and interrelated organizational variables. We know little about involuntary non-use of new ICT at work and how it may arise.

The aim of this article is to extend our understanding of involuntary non-use of new ICT in organizations. An in-depth qualitative case study of large-scale implementation of identical ICT systems in three comparable power grid companies was conducted. The new ICT was intended to fit the tasks and work contexts of three occupational groups: installers, planners, and managers. Planners and managers were accustomed to ICT, while the installers were not. Despite the installers having a positive attitude towards the new ICT, they systematically underutilized it. This article seeks to understand the differences in use between installers (ICT novices) and planners (ICT experts) by exploring power differences between occupational groups and their effect on employees' learning.

ICT implementation often brings on additional organizational changes (Constantinides \& Barrett, 2006), with inherent political processes visible in the narratives of those affected (Dawson \& Buchanan, 2005; Symon, 2008). Due to the rather unexplored nature of involuntary non-use, this study adopted the grounded theory approach in analyzing the narratives of occupational groups. A working conceptualization of involuntary non-use different from resistance was constructed, and a framework for understanding how differences in power may institutionalize involuntary nonuse for one occupational group, but not another, within the same organization was developed.

\section{Involuntary Non-Use of New ICT at Work}

There are several types of technology non-use (Wyatt, Henwood, Hart, \& Smith, 2005). Most studies of digital technology non-use have been conducted in a societal but not work setting (Selwyn, 2003). Involuntary non-use of new ICT at work can be placed in a socio-technical perspective, rather than in a more psychologically oriented one. Also, rather than defining involuntary non-use as solely due to the absence of technology (Slater, 1986), involuntary non-use may occur despite the presence of technology. To put it simply: involuntary non-use of new ICT at work occurs when employees want to use the new technology but are unable to due to factors beyond their control. While technology acceptance is facilitated above all by prior experience, social influence, perceived ease of use, and perceived usefulness (Venkatesh, Morris, Davis, \& Davis, 2003), technology affordance highlights the mutual relationship between technology and the involuntary non-use of new ICT. The unified theory of acceptance and use of technology (Venkatesh et al., 2003) largely builds on the technology acceptance model 1 (Davis, 1989) and 2 (Venkatesh \& Davis, 2000). As an extension of the technology acceptance models, the unified theory of acceptance and use of technology predicts behavioral intention to use technology rather than actual use. A hypothesis inherent in the technology acceptance model is that perceived usefulness and perceived ease of use "... fully mediate the influence of external variables on usage behaviors" (Burton-Jones \& Hubona, 2006, p. 706). A re-writing of this hypothesis is that external forces only have an effect on ICT use behaviors if employees perceive and form an opinion about these. The key to use is therefore employees' positive attitudes (in the form of expectations) towards the new technology. As follows, non-use is a consequence of negative attitudes. In this perspective, use becomes only the responsibility of the individual employee, and non-use should consequently be interpreted as non-acceptance, related to resistance. Likewise, definitions of technology resistance implies a deliberate action or non-action: "Resistance behaviors exist across a spectrum, from being passively uncooperative to engaging in physically destructive behavior (Marakas \& Hornik, 1996), or from lack of cooperation to sabotage (Carnall, 1986)" 
(Lapointe \& Rivard, 2005, p. 464). However, this view does not take into account organizational factors and ICT-organization integration processes as potential use-disabling mechanisms.

Whereas use or non-use as resistance of new ICT at work is described as deliberate, internally caused, and at the individual level, involuntary non-use is unintentional, externally caused, and in general - at the group level. Furthermore, in the unified theory of acceptance and use of technology, perceived usefulness, perceived ease of use, and social influence are assumed to exert a direct effect on behavioral intention to use new technology. However, for involuntary non-use of new ICT at work, these criteria are assumed fulfilled. The involuntary non-users should perceive the new ICT as useful, as possible to integrate in a good way with their work tasks, and have significant others in the organization expecting them to use it. Resistance has in general been described as deliberate behavior, as being directed towards other objects than the ICT itself, and as due to perceived threats in the organizational environment where the non-users' interpretations of the context are considered prime catalysts of ICT-non-use (Lapointe \& Rivard, 2005). On the contrary, involuntary non-use of new ICT at work is not deliberate, the object of non-use is the ICT itself, there is absence of perceived threats, and mechanisms in the context are important in their own right rather than employees' perceptions of these. The study of involuntary non-use of new ICT at work thus requires rethinking about the users and to move beyond an individual focus (Baumer, Burrell, Ames, Brubaker, \& Dourish, 2015).

\section{Power and Power Differences in Organizations}

Hierarchy is a concept for the distribution of power - authoritative (over people) and allocative (over other resources) in organizations (Giddens, 1984; Hatch \& Cunliffe, 2006). Formal power is tied to position, not to person. In this way, hierarchy defines organizational relations. In contemporary organizations, lateral relations increasingly coordinate and shape organizational practices. Competence and the ability to be flexible are sources for power differences in organizations, especially in times of change (Pfeffer, 1981). In the Marx-inspired critical and postmodernist perspectives, power is seen as a way for one group to dominate another group, to achieve ideological hegemony, and/or to marginalize others (Hatch \& Cunliffe, 2006). Power is used to control access to information, agendas, decision-making criteria, and the building of coalitions. Informal power may be acquired through a range of sources; for example, closeness to holders of formal power in the organizational hierarchy (Dalton, 1959) and control over significant resources such as technology (Salancik \& Pfeffer, 1977). Control of new ICT is therefore a source of power, especially as ICT itself can be a tool for control and monitoring. Power-holders define official organizational discourses, which then reproduces the organization's power structures.

Tenure and the inclination to keep it are principal sources of power and political processes in organizations (Bourdieu, 1996). Power relations are reproduced through employees' interwoven practices and constitute social structures (Clegg, 1989). Thus, they affect learning and use of the new ICT. Zuboff (1988) shows how leaders and others can protect and reinforce their respective positions through ICT implementation. As ICT affects organizational processes, those who control the new ICT also control the organization of work. ICTs contain sets of values and implications for the organization of work, integrated by those who had a say in its development and implementation (Zuboff, 1988; Orlikowski, 1992). Those who master the new ICT exert power through their expertise (Boonstra \& Bennebroek Gravenhorst, 1998). The technology affordances and constraints theory offers an additional perspective on technology acceptance and resistance. Technology constraints are present when ICT keeps humans from fulfilling particular goals (Majchrzak \& Markus, 2013). As noted by Gaver (1991), "[a]ffordances are the fundamental objects of perception. People perceive the environment directly in terms of its potentials for actions ...[...] An affordance of an object [...] refers to attributes of both the object and the actor" (p. 79). The more experienced the users are, the more affordances the new ICT represents for 
them. Through their affordances, ICTs contribute to shaping power relations in organizations (Suthers, 2006). Differences in power may therefore lead to differences in ICT use.

When technologies change, work tasks change too. Although not bestowed with formal power, those in control of new ICT may control the re-definition of organizational structures, tasks, practices, and processes. This determines employees' balance between demands, control, and support (Karasek \& Theorell, 1990); in short, it shapes employees' work situation. As structures, tasks, practices, and processes are often adapted to the assumed nature and characteristics of the new ICT (Hatch \& Cunliffe, 2006), the interplay between them will affect employees' work situation and their use of it.

\section{ICT-Organization Integration and Situated Change}

Involuntary non-use of new ICT at work is unintentional, caused by factors external to the employees, and at the group level. To understand it better, ICT-organization integration processes must be analyzed in relation to parallel organizational changes (Constantinides \& Barrett, 2006). Existing frameworks for technology acceptance and use presuppose a rationality of implementation and organizational change. This presupposition does not acknowledge the emergent and interactional way in which learning and new work practices develop (Orlikowski, 1992; Orlikowski 2009).

In the process-based perspective, change is understood as emergent from employees' actions and interactions (Markus \& Robey, 1988; Orlokowski, 1996). Employees' perceptions of the organizational environment, including ICT, are in constant development (Lapointe \& Rivard, 2005; Robey \& Boudreau, 1999). Building on the socio-technical perspective (i.e. Trist, 1981), sociomateriality "...focuses on how meanings and materialities are enacted together in everyday practices" (Orlikowski, 2009, p. 13). Whereas the socio-technical perspective perceives humans and technology as separate systems, sociomateriality acknowledges that these are interwoven and interdependent. Non-use of new ICT is enacted through sociomaterial practices (e.g., Davidson \& Vaast, 2010) and, to study non-use, one must look at organizational factors. Sociomateriality offers a mend where the emergent perspective of change is criticized for downplaying the political aspects of technology (Woolgar \& Cooper, 1999).

Learning is a critical precondition for situated change. Workplace learning as a basis for situated change happens through employees' trial-and-error activities, interaction, and knowledge exchange, in addition to formal training arenas (Orlikowski, 1992). Best practices are established simultaneously with situated learning and change. That means that practices should not be settled a priori to ICT-organization integration, but developed during these processes. Power and learning are intertwined. Situated learning and change requires a balance between demands, control, and support that creates a good learning environment. An imbalance in the distribution of power between occupational groups can create a poor learning environment for those who find themselves in a lower position in the organizational hierarchy, and lead to involuntary non-use of new ICT.

\section{Focus of the Study}

The role of power in organizational change has been emphasized (Buchanan \& Badham, 1999), but in connection with ICT non-use, it has generally been described in terms of resistance behaviors. Social processes modify ICT's effect on employee use or non-use (Mcloughlin \& Badham, 2005; Spicer, 2005), and non-use may be involuntary for those who cannot partake in these processes. With the research problem interpreted in light of the reviewed theory, the study focuses on two main and interrelated areas tied to the institutionalization of power differences and its consequences for employees' use/involuntary non-use of new ICT at work: 
- Political processes in the intersection between the formal and informal organizational hierarchies as antecedents of increased power differences between occupational groups - with knowledge (expertise) and ICT as moderating variables.

- ICT novices' involuntary non-use of new ICT as an outcome of a learning-hostile work environment brought on by power differences.

This operationalization of the research problem promises new knowledge about involuntary nonuse of new ICT at work. We expect to learn more about how power differences affect ICT use and how they may produce involuntary non-use. This includes the influence of external factors on situated learning and use of new ICT; in particular, the factors that mediate the relationship between use and involuntary non-use.

Power differences do not always imply conflict. As this study is to understand how power differences in favor of ICT experts (planners) at the expense of ICT novices (installers) can foster involuntary non-use for the novices, a necessary condition is the absence of ICT-related conflict that could lead to resistance behaviors.

\section{Method}

\section{Research Design: The Grounded Theory Approach}

The aim of this study was to explore how the distribution and exercise of power related to ICT implementation and adherent organizational changes can produce involuntary non-use of the new ICT. The chosen approach to reach that goal was to collect a variety of qualitative data over a relatively extended time period, and to analyze these data through group narratives using the grounded theory approach. Factors such as social and political processes, learning, and contextuality are key (see also Bisel \& Barge, 2011; Kuhn \& Corman, 2003).

Besides following the grounded theory approach, we decided to incorporate into the analysis of group narratives elements from rhetorical analysis. According to Symon (2008, p. 74), "rhetorical analysis provides a means through which a political perspective on technological change can be developed at a micro-discursive level". Through the study of arguments and counterarguments, a rhetorical analysis identifies issues of conflict or disagreement, as well as rhetorical strategies. Its main strength is its emphasis on critical interpretation, which may serve as a useful complement to the analysis of narratives.

The objective of analyzing narratives was used to establish an account of "[t]he way it really happened ..." (Dawson \& Buchanan, 2005, p. 845). This type of analysis is, in other words, useful for reconstructing the meanings, arguments, and behaviors that shaped the use and non-use of the new ICT (Brown, 1998). With the grounded theory approach, the aim is to move beyond mere descriptions towards conceptualizations; this approach is particularly suitable for overcoming issues of accuracy, trustworthiness, and subjectivity of analysis traditionally associated with the qualitative data analysis methodology (Glaser \& Holton, 2004).

A constructivist standpoint pairs well with narrative analysis: "Constructivism assumes the relativism of multiple social realities, recognizes the mutual creation of knowledge by the viewer and the viewed, and aims towards interpretive understandings of subjects' meanings" (Charmaz, 2000 , p. 510). Grounded theory facilitates a move away from a description of what is happening to an understanding of the process (Benoliel, 1996; Corbin \& Strauss, 2008; Strauss \& Corbin, 1998), with a set of tools such as theoretical sensitivity and constant comparison, which suit the study's research focus well. A combination of elements from rhetorical analysis and the analytic strategies of grounded theory are welcome, as "[w]e can use grounded theory methods as flexible, heuristic strategies rather than as formulaic procedures" (Charmaz, 2000, p. 510). 


\section{Participants and Data Collection}

The research materials were collected from three power grid companies in Norway from 2007 to 2010. The data consists of 90 semi-structured interviews and 30 field notes in the form of thick descriptions through open-ended narratives from non-participant naturalistic observation, in addition to hand-written memos made during ten field visits through the four-year period. All interviews lasted from 30 minutes to two hours, and were recorded and transcribed with the participants' consent. The participants in the study were representatives from three occupational groups in the three companies: installers, planners, and managers. The participants were selected in part by managers in each of the three companies based on the number of subjects relative to occupation, and also in part based on information received during interviews. Five researchers participated in the data collection and analyses.

The data collection was undertaken in three phases. These were not defined beforehand, but evolved through the constant comparative analysis and evaluations of the research focus. The interviews were conducted during the first two phases, equally distributed between the companies. Observational data was collected in all three phases, and in Phase III only observational data were collected. Phase I and Phase II lasted 18 months each, and Period III lasted 12 months. See Table 1 for a summary of the data collection distribution. Approximately half of the managers and half of the planners interviewed were interviewed twice, but due to the unpredictable nature of their work, it proved difficult to obtain the same kind of stability with regard to the interviews of the installers.

Table 1: Overview of interviews conducted during the first two phases

\begin{tabular}{|l|l|r|r|r|r|}
\hline \multirow{2}{*}{$\begin{array}{l}\text { Phases } \\
\text { category }\end{array}$} & X & Y & Z & Total \\
\hline \multirow{2}{*}{$\begin{array}{l}\text { Phase I, } \\
\text { months 1-18 }\end{array}$} & Tech. inst. & 6 & 6 & 6 & 18 \\
\cline { 2 - 6 } & Planner & 5 & 5 & 6 & 16 \\
\cline { 2 - 7 } & Manager & 3 & 3 & 3 & 9 \\
\hline \multirow{2}{*}{$\begin{array}{l}\text { Phase II, } \\
\text { months 19-36 }\end{array}$} & Tech. inst. & 7 & 6 & 7 & 20 \\
\cline { 2 - 7 } & Planner & 6 & 6 & 6 & 18 \\
\cline { 2 - 7 } & Manager & 3 & 3 & 3 & 9 \\
\hline Total & & $\mathbf{3 0}$ & $\mathbf{2 9}$ & $\mathbf{3 1}$ & $\mathbf{9 0}$ \\
\hline
\end{tabular}

The respondent-interview was used (Kvale, 1996). A loosely defined interview guide was developed, attempting to investigate why installer use of Power Data was so limited. Based on the codes and categories that evolved during analysis and the coding of group narratives, the research group took a "time-out" after the first 18 months, which resulted in a narrowed focus for the interviews. After having conducted the 90 interviews, observation continued for 12 more months.

\section{Procedure of Data Analysis}

According to Charmaz (2000, p. 510), "[g]rounded theory methods do not detail data collection techniques", and "they move each step of the analytical process toward the development, refinement, and interrelation of concepts". Further, the strategies of grounded theory include: (a) simultaneous collection and analysis of data; (b) a two-step data coding process; (c) comparative methods; (d) memo writing aimed at the construction of conceptual analyses; (e) sampling to refine the researcher's emerging theoretical ideas; and (f) integration of the theoretical framework. There is a constant flow between data, theoretical framework, and analysis.

Following the above guidelines, the data was organized according to occupational groups and not companies. The preliminary and selective coding procedures were carried out by the researchers, both individually and jointly, during the first two phases of the study. Further theoretical sam- 
pling and final categorization were carried out during the third phase of the study. Interpretations were regularly discussed and authenticated with company groups.

The first step of analysis was a preliminary line-by-line coding of incidents, actions, and behaviors in the emerging interview and field note material, which yielded a number of descriptive categories. These were consistently labeled in the text. Recurring codes were identified. In order to move from descriptive to conceptual categories, memo-writing was extensively applied, and selective coding rendered a set of preliminary categories. The second step started with an analysis of the preliminary coding and categories. After this, the categories were discussed, criticized, eventually modified, and either rejected or accepted. Working meetings were held with the respective company groups as a reality check - a strategy of "critical subjectivity" (Reason, 1998). Finally, the categories were re-examined in light of the empirical data, relevant theories, and earlier studies, and were further refined, limited or expanded (see Table 2 for an overview of the synchronized processes of data collection and analysis).

Table 2: The processes of data collection and data analysis

\begin{tabular}{|c|c|c|c|c|c|c|c|c|}
\hline $\begin{array}{c}\text { Data \& } \\
\text { analysis }\end{array}$ & & 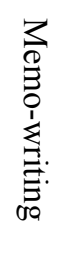 & 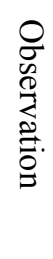 & 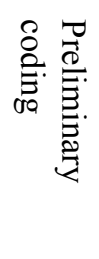 & 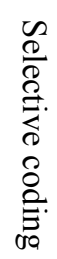 & 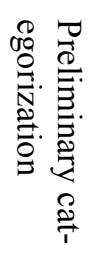 & 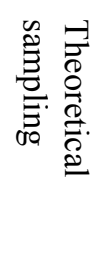 & 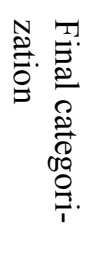 \\
\hline Phase I & $\mathrm{X}$ & $\mathrm{X}$ & $\mathrm{X}$ & $\mathrm{X}$ & $\mathrm{X}$ & $\mathrm{X}$ & & \\
\hline Phase II & $\mathrm{X}$ & $\mathrm{X}$ & $\mathrm{X}$ & $\mathrm{X}$ & $\mathrm{X}$ & X & & \\
\hline Phase III & & $\mathrm{X}$ & $\mathrm{X}$ & & & & $X$ & $\mathrm{X}$ \\
\hline
\end{tabular}

This way of working with the data rendered two main outcomes: group narratives shedding light on the distribution of power and the rationale behind it; and a number of categories relevant to the exercise of power and the possibilities for learning how to use and apply the new ICT.

\section{Results}

The results are presented in three sections. The first section provides background information on the cases and research context. The second section presents findings tied to political processes and power differences in the three companies. The third section summarizes results indicating how involuntary non-use by ICT novices developed from these political processes and power differences, which created a learning-hostile work environment for them.

\section{Cases and Context}

This case study was conducted in the Norwegian power grid industry from 2007 to 2010, with the participation of three power grid companies that all included the three main occupational groups. The three companies were located in different geographical locations. Historically, the Norwegian power grid industry was one of the most successful in the country, and obtaining permanent employment in one of these companies was equal to life-long economic security comparable to, for example, Kodak and IBM in the golden years (Mills, 1996; Mizrahi, 2002). As one installer put it: "When I got a job here as an apprentice right after lower secondary school, my grandfather patted me on the back and told me that now I was set for life!" In the 1980s and 1990s, however, the market was privatized with competition-based acquisition of licenses, and many new players entered the market. The grid companies had to implement severe measures in order to survive, such as downsizing. Around 2005, the companies had regained much of their market 
share, but were now lacking installers and apprentices. The remaining installers were described as "the best in the business" and regularly received calls at home in the evening from competing companies offering them new jobs.

Since the recession, the three companies had repeatedly engaged in a variety of change processes. The companies decided to become increasingly ICT-driven with regard to work processes. After a decade of implementing a variety of ICT-based tools and systems, the new technologies remained heavily underutilized by the installers. This study looks at the implementation of one particular system - "Power Data". Power Data was, among other things, meant to integrate geographical maps of the power grid, both in the ground and in the air, that were intended to serve the needs of all employee groups. Power Data also included functionalities for planners to design outdoor grid operations in the maps, and the installers were supposed to rely on these functionalities in performing their tasks. The installers should also use Power Data to order materials and document their work. Power Data was expected to streamline the workflow between installers and planners, to minimize the need for direct and time-consuming communication, as well as to serve as an administrative tool.

The development, acquisition, and implementation of Power Data were initiated by three planners from one of the three companies. Early on in the process, these three planners established collaboration with two or three planners from each of the other two companies. Together, they defined the specifications of Power Data, its inherent functionalities, and its applications. In their everyday work situation, planners and managers were co-located in the same open-plan office. Planners and managers thus communicated daily, through both formal channels (such as meetings) and informal channels (such as daily chat at each other's desks and in the canteen). Management did not take part in the development and acquisition processes of Power Data, but relied on the planners' understanding of ICT and the organization's needs.

The installers were not included in the processes of acquiring Power Data, and experienced increased isolation. Before Power Data, the installers worked in pairs and interacted with the rest of the organization throughout the day; for example, in the warehouse, the canteen, in direct dialogue with planners and, to some extent, also with managers. Power Data was supposed to replace the need for this interaction: Communication with planners and managers was to be electronic; materials were to be picked up from the suppliers, and they were assigned one car each. They were expected to eat their lunch in the car. All installers were given a personal computer, but they lacked the skills to use it, and the cars lacked signal receptors and computer brackets.

The three grid companies were comparable in terms of size, occupational groups, and chosen technological solutions. The occupational groups were likewise internally homogenous in all three companies in terms of gender, age, and educational background. In the organizational hierarchy, managers held formal power. There was little reflection on the role or position of ICT that officially was spoken of as a tool. Thus, formally, ICTs did not instill a specific power structure. According to the organizational hierarchy, the planners and installers were equal. They fulfilled equally necessary responsibilities and were in an interdependent relationship with each other where work performance partly depended of the quality of this relationship.

In practice, however, power relations were more differentiated. A group of planners consisting of members from all three organizations initiated and participated in the development (together with external software developers) and acquisition of the new ICT. It was, in fact, they who persuaded managers of the necessity of exactly this software. Managers approved, but largely left the responsibility for ICT-organization integration to the planners. As such, the new ICT became the centerpiece of the new organization of work, and the way new practices, routines, and processes were designed affected employees' balance between control, demands, and support. Through their control of the new ICT, planners became far more powerful than the installers. While plan- 
ners with basis in the new ICT defined the new organization of work, the installers increasingly experienced marginalization and had little power to organize their own work, including the use of the new ICT. Informally, the planners therefore held power equal to managers. The following section will elaborate on these power differences.

The information workflow was affected by the informal power distribution. The installers had limited access to Power Data. The system both dictated their workflow and monitored their work performance. The planners largely constituted the link between managers and installers. Controlled by the planners was not only the information given to installers, but also the information they entered into Power Data system-wise. The planners mistrusted the quality of information (documentation) provided by the installers, and served as validators by evaluating it before incorporating into a more permanent part of the system. While on a daily basis the planners communicated with managers, influenced them, and fundamentally controlled the organizational information workflow, the installers received incomplete work- and organization-related information. In order for Power Data to be useful, the data in Power Data needed constant updating. Therefore, documentation was prioritized over maintenance. The documentation process was that the installers would fill out electronic forms in Power Data registration mode while out in the field, and the completed forms would then be automatically forwarded to a planner for control and reregistration in editing mode.

\section{Political Processes and Power Differences}

Data analysis revealed that instead of four groups of narratives as first anticipated - ICT (Power Data), installers, planners, and managers - there were five. Among the planners, there were marked variances, creating two constellations, called "Planners I" and "Planners II". While Planners I displayed a general mistrust of installers' skills and attitudes, Planners II were more positive towards the installers as well as less positive towards Power Data. However, Planners II profited from the same favorable hierarchical position and status as Planners I, and did not speak up about their doubts. Planners I initiated and participated in the development, acquisition, and implementation of Power Data. Planners II were less central.

In order to explore the political processes that took place after the introduction of Power Data, the narratives were analyzed with a special interest in the intersection between formal and informal power. With the formal vs the informal organizational hierarchies as point of departure, the analyses unveiled the nature of dominating assumptions and how they got to prevail. Further analysis concentrated on how these assumptions institutionalized higher organizational status to the ICT experts and lower status to the ICT novices. Relevant to this is the role of ICT-related knowledge and technology affordances. The combined effect of expertise and actual ease of use of the new ICT relates to task-technology fit and contributed to the increase in power differences between experts and novices. Finally, the ICTs' dominating position is looked at in light of its complexity and features tied to information and work flow. The new ICT contributed to differences in power both in its own right through its differential accessibility, and as a tool of control in the hands of experts.

The concept map in Figure 1 shows the major findings about the relationships between occupational groups, the new ICT, power, and organizational status. It unveils the interdependencies between controlling new ICT, defining dominating assumptions in the organization, and organizational status and power. The section below elaborates more on these interdependencies. 


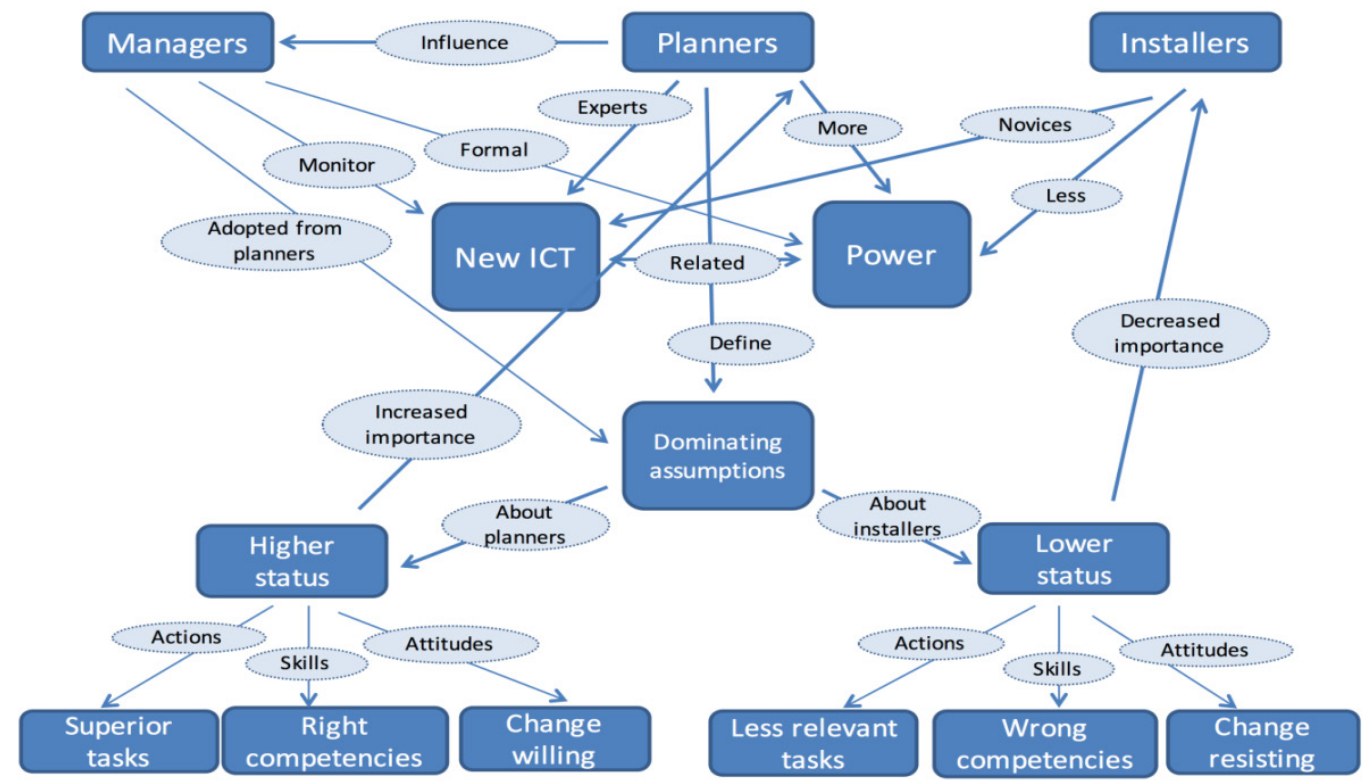

Figure 1: Concept map of development of power differences between occupational groups

\section{Political processes in the intersection of formal and informal power}

As mentioned in the "Cases and Context" section, the development, acquisition, and implementation of the new ICT drastically changed informal power relations in the three companies. Prior to Power Data, planners and installers were perceived equal by others as well as by themselves, and the gap between the formal and informal organizational hierarchies seemed to be smaller. As such, prior to the introduction of Power Data, planners were a more homogenous group in terms of attitudes and opinions than after. As the vision and option of Power Data began to consolidate, those planners most in favor of the system diverged from the more neutral planners.

As the process of acquiring Power Data started, the installers were not thought of as an occupational group relevant to include. The installers were therefore excluded in the consideration of features, task relevance, and field compatibility. In the development of Power Data, features were tailor-made to the planners' responsibilities and work processes, as well as to managers' need for economy monitoring and general administration. This was possible as planners were close to managers, who did not have the same competencies as they did on complex ICT systems. For management, economy was the key priority: "I want to prioritize what yields the highest income, but the company has certain statutory obligations, and that's a dilemma" (manager). Processes tied to Power Data were outsourced to the ICT experts. This exclusion of the ICT novices regarding the new ICT implied a downgrading of their skills and a marginalization of their organizational status. This marginalization was transferred to those of the installers' tasks that did not generate income. Consequently, grid maintenance operations - important also for the installers' safety - were under-prioritized. The installers experienced not being heard: "We rarely report how bad it really is - no one would believe us, and nothing would be done. [...] Many of the old stations pose a threat to our lives; we have asked for years to have them rebuilt, but nothing happens" (installer). This also relates to task performance: "I was asked to control 750 outdoor transformer stations by driving by and see if everything seemed ok from the outside. What do they want us to check? Graffiti?!?" (installer).

Different occupational groups perceived the matter of inclusion (planners) and exclusion (installers) differently. While the installers clearly expressed exclusion, the leading planners (Planners I) did not share their view: "All professional groups were included in the development of specifica- 
tions and functionalities" (planner I). During the interviews, it became clear that the installers had not had a say in the processes per se, but their tasks and work processes were mapped by the planners. This mapping was incomplete and left the planners with a faulty understanding of critical features of the installers' work and situation. This differential treatment of occupational groups seems to be the basis for the differences in power that arose with the introduction of Power Data. The defective understanding led the dominating planners to developing assumptions about the installers that heighten planners' status at the expense of installers' status. These assumptions referred to dichotomies tied to attitudes, skills, and actions, with planners at the positive end. Due to planners' expert status and closeness to managers, these assumptions were allowed to institutionalize into official organizational norms and thinking - in practice shared by managers and the dominating group of planners. Managers adopted these assumptions, and as they were not an active part in the ICT-organization integration processes but relied on the information they received from the planners, their formal decisions were colored by the planners. The dominating planners mistrusted the installers' attitudes and motivations towards the new ICT, and as a result characterized the installers as being resistant to using Power Data. This view was shared by managers. Therefore, planners were labelled "change willing" and installers as "change resisting". As the companies were in a process of intense digitalization, tasks directly performed using the new ICT were ascribed more relevance and importance than manual tasks that did not require ICT-use. Planners as ICT experts were seen as 'better skilled' for the future than installers. Although both the managers and the other fraction of planners to some extent questioned the functionalities of Power Data and the new organization of work, they did not challenge the dominating assumptions.

These political processes took place in the intersection of the formal and informal organizational hierarchies, and were therefore hidden - especially for the installers.

\section{Knowledge, tasks, and technology affordances}

ICT-based expertise - over formal power - was the main criterion for inclusion in the processes tied to development, acquisition, and implementation of Power Data in the three companies. Having 'relevant' knowledge and competencies was therefore crucial in order to keep or gain more power. The dominating fraction of planners used their power to institutionalize their assumptions through managers - assumptions about the new ICT, about themselves and the installers, about best practices, and about the organization of work. An effect of this institutionalization was higher organizational status for the planners and lower organizational status for the installers.

This prevalence of ICT-based work over manual work and of ICT-based knowledge over practical skills is by no means new. These findings confirm this tendency. As a result, the ICTorganization integration was adapted to planners' work tasks and processes. Much of the plannerinitiated mistrust towards the installers stemmed from a belief that they lacked both competencies and interest in any ICT-related task, and thus that their work and performance would be poor in quality: "I don't trust documentation done by installers", and "They often don 't even bring their computers with them", and "Some installers think that documentation is just for their own use" (planners I). This, in the planners' eyes, justified their domination. Another argument for staying in control was the superiority of planners' tasks: "Economic responsibility is the responsibility of the planners, not of installers" (planners I), and for the sake of data quality: "I see no benefits in registering data directly out in the field. It's hectic, there are many disturbances, and weather conditions complicate the use of digital equipment" (planner I). This gave the planners a pretext for controlling not only the formation of new tasks, processes, and routines for work performance, but also the information workflow. They were gatekeepers and validators of the information exchange between installers and managers. 
Consequently, the hidden political processes furthered the assumptions, which increased the differences in power between installers and planners. The differences led to an improved tasktechnology fit for the planners, but to a poorer fit for the installers. As the new ICT and new organization of work were set to match the experts' tasks and competencies, the increased differences in power resulted in a more challenging work situation for the installers: "Map backgrounds take a long time to load and often result in an error. You are therefore forced to go back to the office to check.", and "The will to use and implement new tools is very high, but when you have to sit in your car outside gas stations in order to get online, it's a hassle" (installer). While experts seemed highly competent and important in the new organizational order, the installers appeared unskilled and marginal.

The complexity of Power Data in particular strengthened this perception of qualified experts and unqualified novices. As theories on technology affordances imply, the better the fit between task and technology, the more application areas will develop. Good task-technology fit is a selfreinforcing mechanism. The better the initial fit is, the better the users are able to continuously adjust tasks and technologies and to find new areas of use. The same goes for the novices - the initial poor fit between their tasks and Power Data also became a self-reinforcing mechanism. As the installers were never able to start using the new ICT, it was impossible for them to adjust it to their tasks. In this way, task-technology fit and technology affordances represented political processes, or at least they strengthened the tendencies of underlying political processes tied to the ICT-organization integration. The relevance of tasks that were inherently different in nature was judged according to the same ICT-based criteria, contributing to power differences. These power differences either increased or decreased employee status accordingly, based on the institutionalization of dominant assumptions and the close relationship between power and ICT.

Planners II questioned the dominating assumptions about the installers as incompetent and useresisting: "We have some of the best installers in the country, but there are too few of them" and "The installers don't have the time to perform documentation tasks in the field". Planners II also admitted that many planners had a poor understanding of the installers' work: "I' $m$ an old installer. I think the planners should spend time with the installers in order to understand their work processes." They did not, however, speak up about these issues.

\section{ICT - Simultaneously a power-agent and a power-tool}

The planners' control of the design and implementation processes of Power Data, along with their mistrust and exclusion of installers therein, made the system an agent of power in its own right through the way it dictated installers' tasks and work processes, making it impossible for them to confirm a finished job before entering the relevant data into the programs. In this way, Power Data exerted power over the organization of work. Power Data exerted power over the installers, in that the system favored skilled planners over unskilled installers, and suited the tasks of planners but not that of installers. It also enabled decentralized control of the installers' actions by the planners, as the planners used Power Data to monitor the installers' work performance and to control and validate the information entered. Power Data became the planners' tool for power.

Power Data ideally contained complete and updated information about the field: where underground cables, power pylons, and transformer stations were located, voltage, whom they served, functionalities for calculating amperage, cost, time-registration, and quantities of material to order, and so forth. With planners as experts, Power Data was designed with a high entry level deemed necessary due to the high level of organizational complexity. However, as the planners had a faulty understanding of installers' work, "Power Data doesn't fit with how people work" (installer). Likewise, computer literacy was insufficiently mapped: "One person did a lot of the evaluations single-handedly" (installer). Inherent in Power Data was the notion of a self-

explanatory system that all employees, with some help from the manual, would eventually be able 
to use as intended without much difficulty. While Power Data allowed the expert planners to apply various ICT programs in an increasing number of new areas, the installers were lost.

Represented by its complexity, its steering of tasks and work processes, and the use of it as a tool for monitoring and control, Power Data enforced the skepticism about installers' ability to apply the new ICT as prescribed in their everyday work, and consequently the installers only had access to the "lower level" functions of the system. In other words, through their participation in the development of Power Data, the dominant group of planners incorporated their assumptions into the functionalities of this and other systems. Thus, the new ICT contributed not only to the institutionalization of increased power differences between experts and novices, but also to justifying the prejudices inherent in these assumptions.

Table 3 presents some exemplary statements by interviewees pertaining to the development of power and status differences. In particular, these statements highlight the perceived necessary complexity of Power Data, the marginalization of the installers as an occupational group, and the dominating assumptions that allowed the power differences to institutionalize.

\section{Table 3: Examples of arguments that support the development of power and} status differences

\begin{tabular}{|c|c|}
\hline Complexity & "A complex user interface is necessary in order to fit task complexity." \\
\hline $\begin{array}{l}\text { Quality of work perfor- } \\
\text { mance }\end{array}$ & "Several "layers" of registration is necessary to ensure proper quality." \\
\hline Usability (ease of use) & "Power Data is self-explanatory through consistent use." \\
\hline \multicolumn{2}{|r|}{ Exclusion and marginalization of installers (installers) } \\
\hline Not heard & $\begin{array}{l}\text { "Earlier, we were taken seriously and upgrades were more automatic, with } \\
\text { long term plans. Now they are focusing more on new business areas and the } \\
\text { grid literally falls to pieces." }\end{array}$ \\
\hline $\begin{array}{l}\text { New ICT is difficult to } \\
\text { apply }\end{array}$ & $\begin{array}{l}\text { "Assignments and tasks are removed from the system before they're fin- } \\
\text { ished; we're not able to give final approval as we're supposed to." }\end{array}$ \\
\hline \multicolumn{2}{|r|}{ Dominating assumptions (planners and managers) } \\
\hline $\begin{array}{l}\text { Mistrust installer compe- } \\
\text { tences }\end{array}$ & $\begin{array}{l}\text { "I think the installers are afraid to use the systems and they don't really want } \\
\text { to; they don't have the skills." }\end{array}$ \\
\hline Installers resist ICT use & $\begin{array}{l}\text { "With regard to competence, the installers drag their feet, but they just have } \\
\text { to learn it!" }\end{array}$ \\
\hline $\begin{array}{l}\text { Planners should define } \\
\text { work processes }\end{array}$ & $\begin{array}{l}\text { "We need to split the tasks - a more defined planner-doer model would give } \\
\text { us better oversight of the processes." }\end{array}$ \\
\hline $\begin{array}{l}\text { Planners must control doc- } \\
\text { umentation }\end{array}$ & $\begin{array}{l}\text { "Data capture and data quality are what cost money; the installers can't be in } \\
\text { charge of that." }\end{array}$ \\
\hline $\begin{array}{l}\text { Manger-supported acquisi- } \\
\text { tion processes }\end{array}$ & $\begin{array}{l}\text { "We had the full support of management in the acquisition and specification } \\
\text { process." }\end{array}$ \\
\hline
\end{tabular}

\section{Involuntary Non-use of New ICT: A Result of Power Differences}

This section presents findings that shed light on the nature of novices' involuntary non-use of new ICT at work, as something more than just the opposite of acceptance, and different from resistance. Novices' attitudes and motivations are compared to the salient variables of the technology acceptance models/the unified theory of acceptance and use of technology, as well as the parameters used for describing resistance. The results further link involuntary non-use with the balance between demands, control and support, and indicate that this is a basis for its extrinsic nature. Mechanisms in the intersection between technology, organization, and employees were 
found to exert an influence on involuntary non-use, which supports the notion that involuntary non-use is more a system phenomenon than a psychological one. Involuntary non-use seems to be more affected by interplay of elements in the organizational environment rather than by the individual employees' perceptions and attitudes, and is thus more influenced by system-related factors than psychological ones. This, together with the finding that dominating organizational assumptions are important factors in the development of power differences between occupational groups, indicates that involuntary non-use may be a group-level phenomenon. Based on analyses of group narratives, the relationships between power, employees' work environment, and situated learning are closely examined.

Figure 2 shows how differences in power may lead to differences in the use of (new) ICT in an organization. Those who hold power control the new ICT, and define a new organization of work with ICT as the centerpiece. There is a reciprocal relationship between the new ICT and the new tasks, practices, and routines, which affect the nature of working conditions and learning environments.

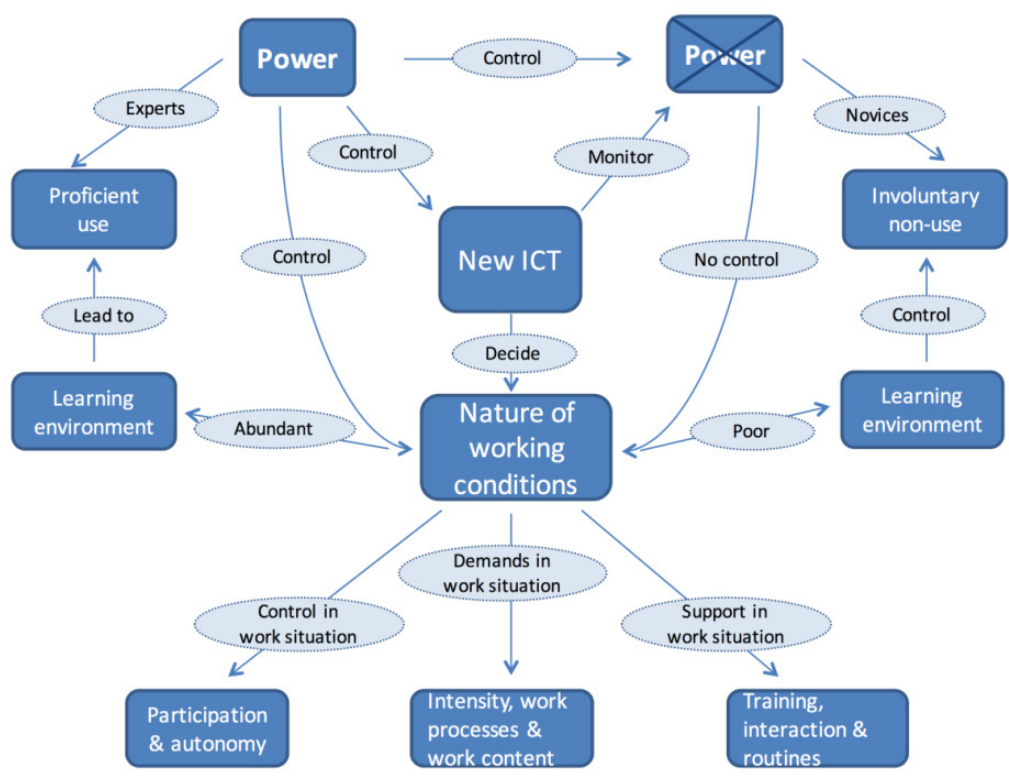

Figure 2: Concept map of the effect of power differences on the use and non-use of new ICT

\section{Involuntary non-use as unintentional, group level, and externally based}

The installers expressed a high level of motivation to use new ICT in general and Power Data in particular. The interviews yielded several affirmative comments about this, e.g., "The future is digital - live maps that work would be great!" (installer) and "The computer will be a great tool once we learn how to use it!" (installer). This pertained to both perceived usefulness and perceived ease of use. According to the technology acceptance model, these factors promote user acceptance of new ICT. This did not change the fact that the ICT novices greatly underutilized Power Data, despite positive attitudes and a high level of social influence. The positive attitudes also indicate that the novices' non-use was not an act of resistance; in general, they embraced the digitalization of the organization. This supports the understanding of ICT non-use as unintentional and thus involuntary. This also supports an understanding of involuntary non-use from the system perspective - it is not based on an inner, psychological emotion or perception. 
The assumption by the leading fraction of planners and managers about the installers resisting using Power Data was clearly incorrect. Planners II were more conscious of the challenges in installers' work situation; for example, their lack of time to meet competing demands. Both planners II and managers questioned the fragmentation of work processes. However, managers and planners II both profited from this situation in terms of the types of work tasks and status, which seemed to be the reason why actions were not taken to solve the issue of power differences. The dominating assumptions stigmatized the installers as a group. The external conditions that contributed to the establishment of involuntary non-use affected all those in a certain role or position. In this respect, involuntary non-use is a group-level issue.

The analyses of narratives uncovered eight working conditions in particular that were changed following the implementation of Power Data for both installers and planners. These working conditions are dichotomous in that they may be positive or negative for employees' work situation. Here they were found to be positive for the experts as they were the power holders, and negative for the novices. The interrelationship between power and the quality of the work situation forced the ICT novices into a situation of involuntary non-use, where working conditions constituted external barriers towards apprehending adequate user skills. The working conditions contributed to the reinforcement of power differences through employees' everyday practices; while the installers experienced a loss of power due to these changes which reinforced marginalization, the planners experienced an increase in organizational centrality and power.

The first working condition is participation: the degree to which an employee is able to influence his/her work situation. The installation of Power Data allowed planners to influence everyday work, but yielded reduced participation for installers. Tied to participation is autonomy, defined as the freedom to control: (1) work method, (2) scheduling, and (3) evaluation criteria (Breaugh, 1989). The planners experienced increased autonomy through upgraded skills and new ICT: "The planners specify most of the evaluation criteria." (planner). This negatively affected the autonomy of installers: "Decisions are made over our heads!" (installer).

The next cluster consists of three working conditions: training, interaction, and routines. There was no plan for training in the organization, which was questioned by a planner II: "I can't see that anyone has given much thought to the changes to come, [...] and an effort must be made to prepare people for the changes to come." (planner). The planners had advanced skills and a sheltered work situation: "I need time for trial and error and relief from my ordinary tasks. I work from home at least a couple of days a week." (planner). The installers lacked basic skills and training: "The installers have struggled. I had some training for them to begin with. But I have no idea of where they are now." (planner). Both planners and installers pointed at interaction with others as crucial for building expertise. The planners enjoyed a high level of interaction: "Management understands my needs" (planner), while the installers experienced less interaction: "The installers have been so divisionalized that we hardly know what the others do anymore" (installer). A challenge for the installers was that the new routines did not constitute functional guidelines for action. Routines were unclear and subject to frequent modifications: "We miss clear instructions for work processes, routines and procedures" (installer).

The final cluster of working conditions consist of intensity, work processes, and work content therein implying adequacy of technological solutions. The planners got to design new work processes, leaving the installers to adapt as best as they could. "The installers weren't used to and had no culture for documentation. We therefore defined the system for them." (planner). The installers experienced less task variety and a more fragmented work process: "In the earlier systems, we registered the data ourselves; now we just collect it." (installer). Increased monitoring and increased responsibilities contribute to work intensification (Delbridge, 2007). This is in line with the findings here: "Some planners can monitor whether the installers have the computer turned on or not" (planner), and "Installers usually register data into the forms at home in the 
evening on their own time; we don't have the time to do it after each job" (installer). Planners got a new tool to manage work intensity, while installers experienced an increase in job demands. Planners defined Power Data and its use, but managers were not that enthusiastic, but gave their blessing: "I don't think that management really has given any thought as to what the data is for" (planner). The planners found a good fit between the chosen technological solutions and their tasks. The installers pointed out that they only had access at a low level, and that the system fitted poorly with their tasks: "The poor integration of technological tools in the car is hazardous when out driving; I get my share of honking. I asked my boss for a car antenna. He didn't have one!" (installer). The dichotomous nature of these working conditions and their differential expression for planners and installers is exemplified in Table 4.

\section{Table 4: Final coding categories of dichotomous work dimensions showing power distribution}

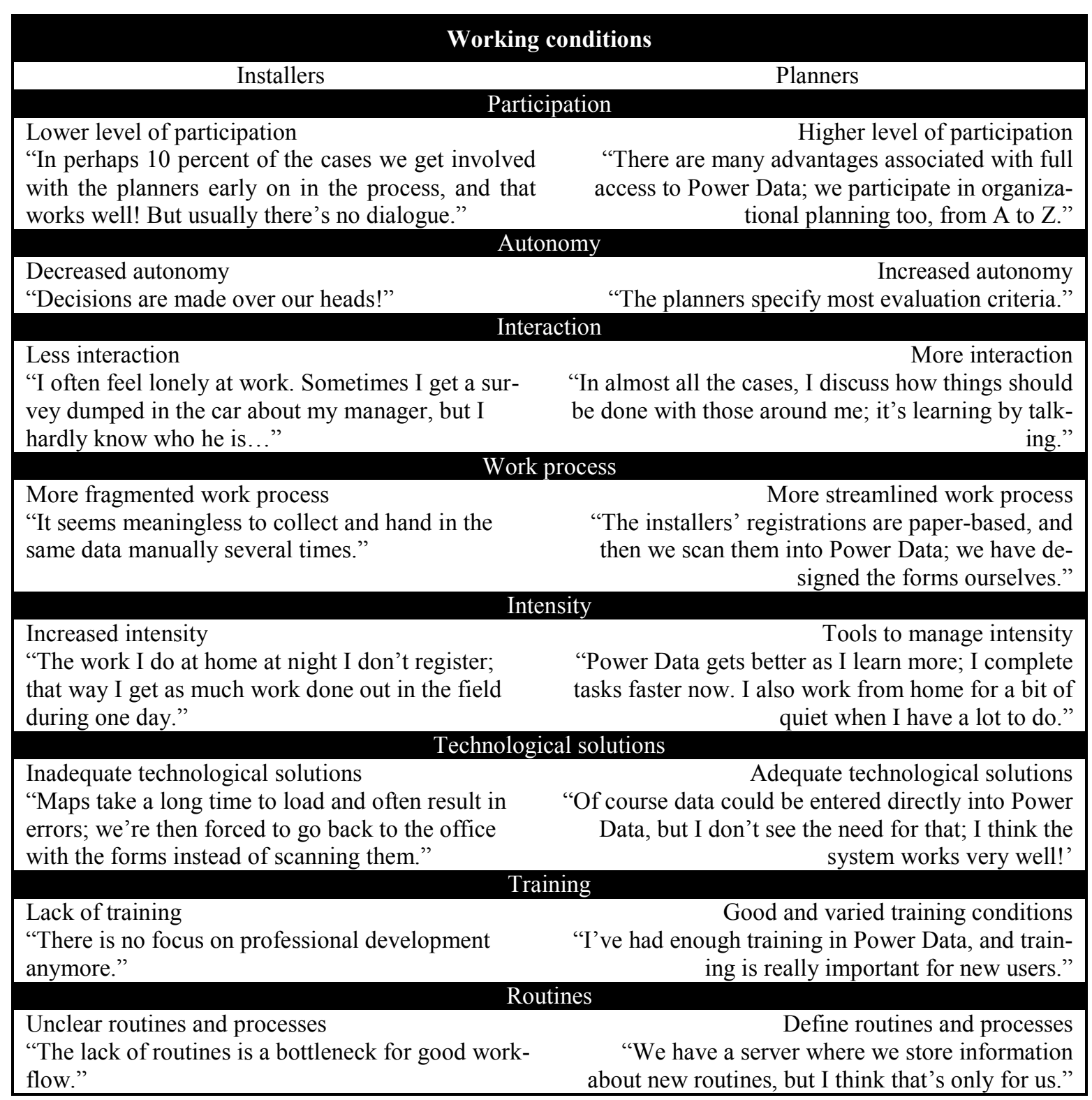




\section{The relationships between power, work situation, and learning}

While the installers were highly motivated to implement Power Data, a few installers also expressed that their attitudes would be even more positive and their motivation even higher if they were given more information and allowed greater involvement: "Our sense of responsibility would be far higher if we could enter data directly" (installer). As it was, they did not feel informed or involved: "We have never been given any reason for why we have several systems or why things should be done this way or that way" (installer). There was a general consensus that the functionalities in Power Data were bad, both in terms of the software itself and with regard to necessary support. The installers did not get the technical support they needed: "The support there is not for us. In nine out of ten cases, they just tell us to turn the computer off and then on again" (installer). The installers experienced a loss of power through the re-organization of work, lack of involvement, the high-level user interface of Power Data, and its bad fit with their work tasks. They felt no longer being able to perform their tasks the way they were supposed to be done.

Managers presumed the installers' intention to use Power Data was based on what they were told by Planners I. However, they also questioned Power Data: "The grid owner was not thoroughly represented or informed" (manager), and "Power Data is too weak as a supportive tool for managers in their decision-making" (manager). Some of them did not have full faith in Power Data's functionalities: "I don't really trust the calculation functionality in Power Data" (manager). They also pointed out problems with procedures: "I may read somewhere how things are supposed to be done, but it doesn't work like that" (manager). Managers also questioned the fragmented work processes: "It would be good to integrate functions in the value chain" (manager), and role division: "There is an unclear division of roles in the collection of documentation" (manager). Management also reflected on the distribution of power: "There is a shift in status/ power relationships because of new technology - is this an impediment to efficient use?" (manager).

The findings point to the low quality of ICT-organization integration processes due to an unequal distribution of power between occupational groups equally central in the formal organizational hierarchy. ICT experts were unofficially given the responsibility for the ICT-organization integration. The ICT was fitted to experts' tasks and workflow, which were reorganized in a way that permitted the experts to control the novices' work situation and performance, directly by defining new working conditions, and indirectly through Power Data. While the experts molded a work situation that for their own part furthered learning and skill development, the novices experienced a deterioration of their learning environment, characterized with lack of participation and autonomy, lack of training, removal of arenas for interaction, inadequate work routines, increased work intensity, fragmentation of work processes, and inadequate technological solutions. Put together, these working conditions created a learning-hostile work environment that fostered involuntary non-use of the ICT by novices. See Figure 3 for a visualization of these interacting factors.

The experts, on the other hand, had a learning-friendly work environment that furthered the development of new skills both formally through training and informally through the possibility by trial and error. A learning-friendly work environment also has to do with the nature of the execution process. See Figure 4 for a visualization of how power in relation to new ICT as well as to the ICT-organization integration processes leads to high-level use of the new technology. 


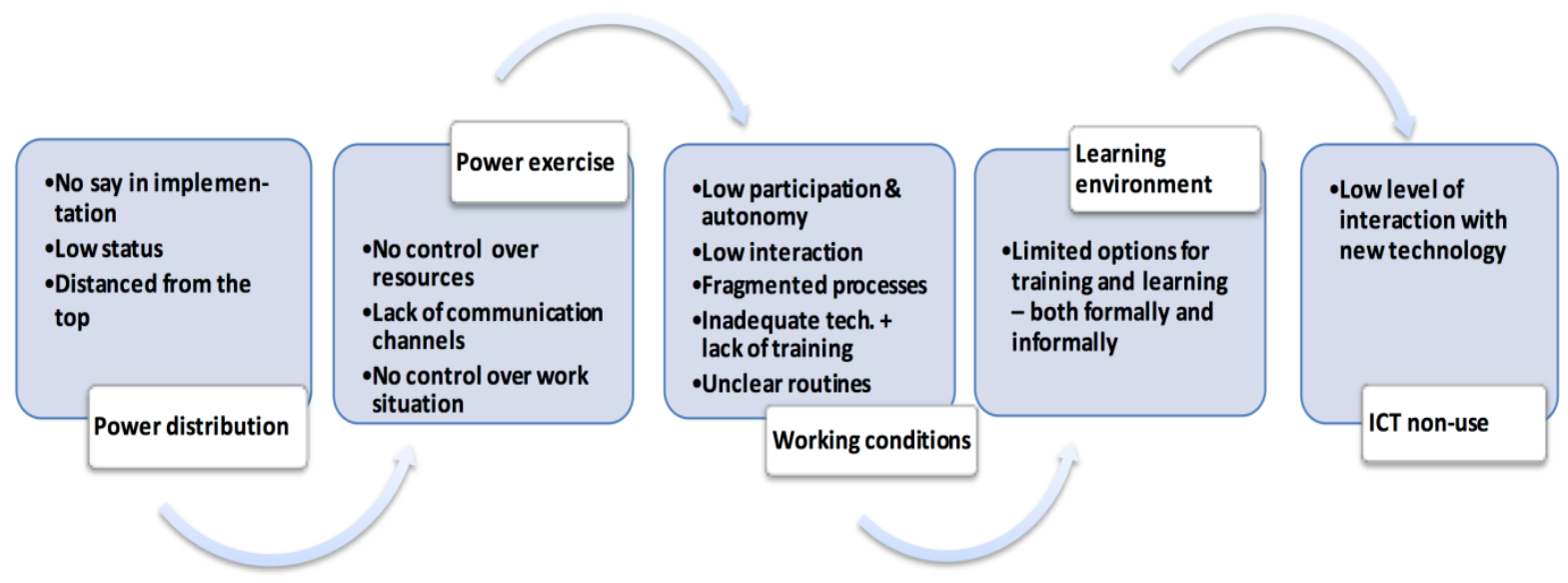

Figure 3: How lack of power can lead to involuntary ICT non-use on the group level

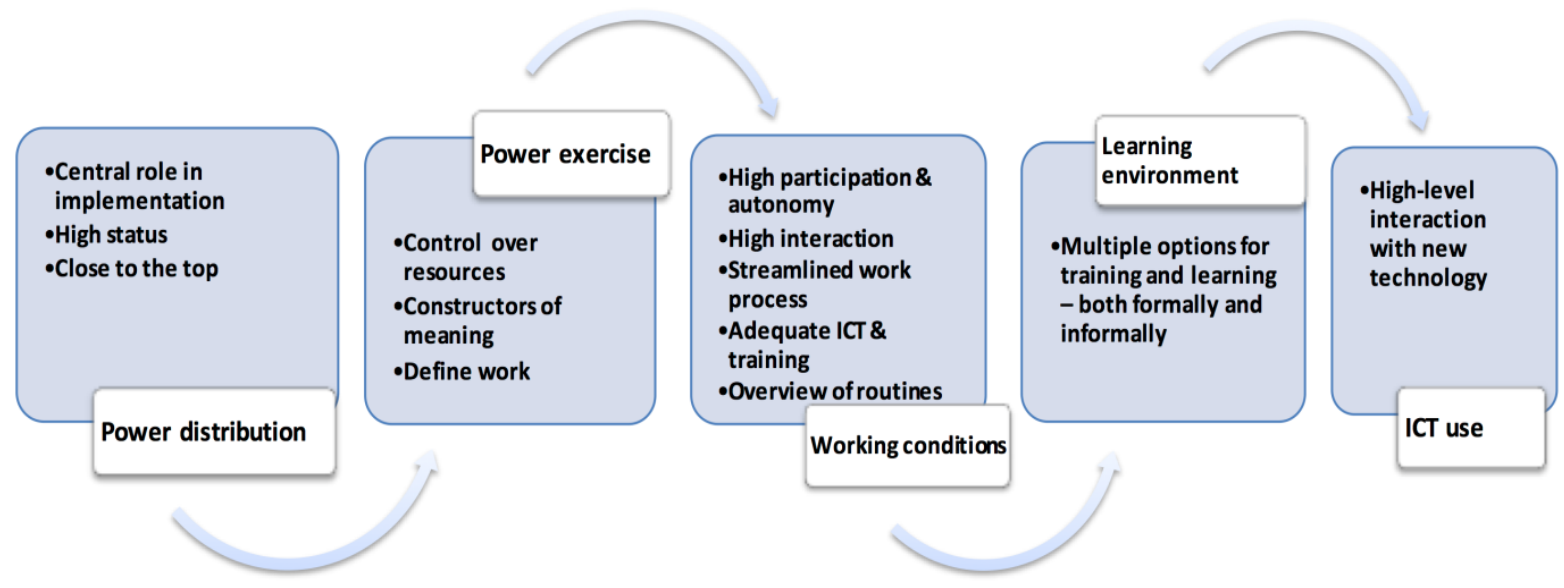

Figure 4: How power furthers ICT use

\section{Discussion}

The key findings of this study evolve around the conceptualization of involuntary non-use - as a systems phenomenon, unintentional, at the group level, and externally caused, as well as the effect of power differences on the use and non-use of new ICT at work. Although involuntary nonuse of technology is not a new concept, it has neither been adequately conceptualized nor thoroughly investigated in the past. As any phenomenon, involuntary non-use of new ICT in a work setting may vary, depending on a range of variables. It is therefore necessary to consider this conceptualization of involuntary non-use and the idiosyncratic conditions inherent in these particular cases in light of existing literature. In this study, the role of the new ICT is salient. Rather than treating it merely as a work requisite, its part in organizational political processes was explored. The interplay between power and ICT influences working conditions that affect the balance between employees' experienced levels of demands, control, and support. Differences in power represented by the status of employee groups in the intersection of formal and informal organizational hierarchies yielded differential working conditions for the implicated groups. When these working conditions are evaluated as a whole in terms of their impacts on employees' daily work, they influence the quality of the organizational learning environment. In this sense, power and status become critical for learning and situated change. These findings require further attention based on what is already known about learning and situated change. 


\section{A New Conceptualization of Involuntary Non-use of New ICT at Work}

The conceptualization of involuntary non-use of new ICT at work developed in this study has two preconditions: (1) the technology is accepted in terms of behavioral intention to use the new ICT - with reference to the theoretical frameworks of the technology acceptance models' and the unified theory of acceptance and use of technology (Davis, 1985; Venkatesh et al., 2003); and (2) the technology is actually present/installed (Slater, 1986). These preconditions were met in all cases of the three power grid companies. This study confirms that involuntary non-use of new ICT at work is a phenomenon that is beyond the scope of technology acceptance theories, and also different from the phenomena of resistance. When these preconditions are met, the non-use of new ICT in organizations is unintentional, and thus involuntary.

Consideration of more elements when investigating the interaction between users and technology was recently called for (Baumer et al., 2015). The claim that involuntary non-use of new ICT may be at the group level, responds both to this call and to previous research on non-use (Lapointe \& Rivard, 2005). In these cases, the different occupational groups were internally homogeneous. It is likely that factors in the work situation affect employees that are members of a specific group more or less in the same way. Drawing on social identity theory (Knippenberg \& Schie, 2000), likelihood is equally high that these factors will foster more or less the same cognitive processes and the same behavioral responses for members of the same group. Thus, involuntary non-use at work can be an unintentional, group-level behavior, caused by group-level mechanisms. Also there are two preconditions that should be met in order to characterize involuntary non-use at work as a group-level phenomenon: (1) the groups in question are internally homogenous; and (2) mechanisms in the work environment affect the group members in the same way.

The conceptualization of involuntary non-use of new ICT at work as a group-level phenomenon has one major implication, which is that involuntary non-use is a system-induced phenomenon rather than a psychological one. What differentiates involuntary non-use from resistance is that the barriers of use are not psychological reactions, but external and related to factors intrinsic to the employees' work situation. It follows that involuntary non-use of new ICT at work is externally caused. This is largely supported by the findings and will be discussed in greater depth in the next section. The unified theory of acceptance and use of technology (Venkatesh et al., 2003) postulates that facilitating condition is the only variable that has a direct effect on user behavior, which substantiates this understanding of involuntary non-use. Behavioral intention to use new ICT precedes actual use. One key criticism of acceptance theories is that they usually measure behavioral intention to use new ICT in organizations à posteriori to the ICT-organization integration processes. In line of this criticism, this study finds that involuntary non-use behavior occurs after attempts at ICT-organization integration. Therefore, it is plausible that involuntary non-use behavior is caused not only by the absence of facilitating conditions, but by conditions that actually obstruct use.

The conceptualization advanced here is supported by the findings of this study as well as that of previous research. However, one factor in particular necessitates further consideration. The main disparity between the occupational group that used the new ICT and the group that did not, besides closeness to managers, was previous experience with the new ICT. The users were labelled ICT experts, and the non-users were labelled ICT novices. Previous experience is clearly not a condition external to employees. A possible criticism of the conceptualization is that the non-use in the case organizations evidently applies to ICT novices. Is it possible that the lack of ICTbased skills, not the barrier in the work environment, mainly inhibited the use of new ICT? The argument against this apparent discrepancy is that skills and experience are abilities (and sources of power) acquired from learning and are results of situated change that involves new ICT. Compared to novices, ICT experts have an advantage of mastering the new ICT while taking part in its 
development, and their previous experience helps them integrate the new ICT into their daily work far more easily. Involuntary non-use arises when the novices are not allowed to partake in eventual development processes and to learn, understand, and use the new ICT. Previous experience is included in the unified theory of acceptance and use of technology (Venkatesh et al., 2003) as a moderating variable, not directly influencing either behavioral intention or behavior itself. An important clarification is that although experience is personal, it should be taken as a moderating factor, not a direct cause of use or non-use. Furthermore, experience can be systemrelated in that gaining experience is an outcome of an adequate work situation with a high-quality learning environment.

The level of specificity in this conceptualization of involuntary non-use of new ICT at work is unprecedented. The next section discusses the tight interrelationships between power/status, ICT, learning, and situated change. Earlier research has shown the tight interrelationship between knowledge and status (Alvesson, 1993). This study goes a step further by elucidating how differences in power leads to involuntary non-use of new ICT by novices that are at the bottom of the organizational hierarchy.

\section{Power Differences, Learning, and Situated Change}

For gaining power in the "new digital organization", there were two key requirements: closeness to ICT; and closeness to management. ICT experts initiated, as well as executed, the acquisition and development processes of the new ICT, arguing for its indispensability. They were active in developing the design and related solutions of the new ICT according to what they knew they needed and to what they thought the other employees in the organization needed. The findings show that whoever is close to the new ICT may seem authorized to propose designs for the organization of work, work performance, and work processes based on that particular ICT.

ICT is given a greater centrality in this study than what often is the case. This is done purposefully. Critics have pointed at how much research treat technology as a "black box" (Orlikowski, 1992). When the target of study is power and political processes that precede involuntary non-use of new ICT, the assumptions and organizational norms that are built into the technology and its prescribed use become crucial sources of data. An important contribution of this study is that it sheds light on the tight interrelationship between ICT and power, and how experts become autocratic pseudo-managers that function as gatekeepers for the flow of information and the development of new knowledge. Earlier literature has shown how patterns of power are reproduced through everyday organizational practices (Clegg, 1989). ICT as a tool for power is not a new perspective (Zuboff, 1988), but it is novel to apply a framework of sociomateriality (Orlikowski, 2009) to understanding involuntary ICT non-use. The combined closeness to formal power holders and to ICT allowed experts to shape and control daily organizational life. This is also an example of how lateral relations steer organizational practices partly outside of the formal hierarchy.

There is little doubt that there is a connection between expertise, power, and new technology. This study shows how experts as autocratic pseudo-managers shape the working conditions critical for employees' balance between demands, control, and support (Karasek \& Theorell, 1990) in their everyday work. It reveals a link between power and ICT, psychosocial work environment, and learning and situated change. This is supported by previous studies that have found political processes inherent in the interdependencies between technology, employees, and organizational practices (Davidson \& Vaast, 2010). Based on differences in power, experts and novices are subject to different working conditions critical for the quality of their learning environment at work.

Working conditions can favor one employee group in an organization, but be disadvantageous to another at the same time. Working conditions are manifestations of power. They govern and 
structure how employees work. Those who hold power can shape working conditions to their favor. The analyses revealed eight working conditions that had changed in parallel to the ICTorganization integration processes. These working conditions have an inherent duality in that they can either further ICT use, or function as barriers towards use. They influence the organization of work, processes, and practices, and are shaped by employee behaviors. In this case, they were rationalized as given by the nature of work, of which technology was part. The analyses show that working conditions can inhibit ICT use by creating a poor learning environment for employee groups, despite their will to actually use it. As such, working conditions can create involuntary non-use. In order to understand their importance for employees' levels of demands, control, support, and learning, the relevance of these working conditions is briefly evaluated.

Participation has been associated with "... high levels of job satisfaction, commitment, involvement, performance and motivation, and low levels of physical symptoms, emotional distress, role stress, absenteeism [...] and turnover" (Spector, 1986, p. 1005), and is considered crucial for successful organizational change (Klev \& Levin, 2012). Through participation and autonomy, employees construct meaning tied to tasks, processes, and technology. Participation and autonomy express power in terms of position and tenure. Those who participate and are autonomous feel ownership of interpretations and meanings, and may define the organization of tasks and processes.

Increased work intensity and inadequate technological solutions may also disable ICT use. A work situation with high demands and low levels of control has high intensity, which contributes to constrain learning, and often leads to a poor learning environment; for example, the demandcontrol-support model (Karasek et al., 1998). The good design of new ICT vis-à-vis employees' work tasks is a facilitating condition (Venkatesh et al., 2003). Adequate technological solutions help alleviate work intensity, while inadequate technological solutions add to it. If work intensity is beyond the employee's control and the technological solutions are inadequate, these working conditions together represent an impediment to the integration of any new ICT. Those employees who experience the best technological fit with their tasks hold power, in that they are able to manage their work intensity in a good way. They also control task performance and work processes. High work intensity and a poor technological fit contribute to involuntary non-use.

Interpersonal relationships and social dynamics are important for learning and change (Armenakis, Harris, \& Mossholder, 1993). Task uncertainty affects both performance and the effect of increased autonomy (Cordery, Morrison, Wright, \& Wall, 2010). Participation and ownership of interpretations are constructed through interaction and work processes that make sense. Autonomy, participation, interaction, and a system-level understanding are necessary for making sense of the new ICT. Therefore, interaction opportunities and understanding the meaning and coherence of work processes are sources of power, as they constitute the foundation for partaking in decision-making. This is a platform for learning and development, which is also a source of power. A lack of interaction and understanding at the system level can contribute to a lack of learning, and thereby increase of involuntary non-use.

Learning through formal training and informal trial and error in a manner that allows for improvisation (Boudreau \& Robey, 2005) is key in the acquisition of new skills. The novices were unable to learn how to use and implement the new ICT in their everyday work due to lack of training. The planners, however, received satisfactory training and had the opportunity for trial and error. Through continued interaction with the new ICT, they gained more expertise and formed the new routines that guided the organization of work. This is an example of technology affordances: how the interplay between ICT and its users shapes new routines and prescribed practices (Suthers, 2006). Routines that work for one employee group may not work for another. Unpredictability may be "self-justifying", in that it is inherent in a technological complexity that only can be managed and mastered by those who know how to use the new ICT. If well-functioning routines re- 
quire interaction between the ICT's apparent and performative aspects (Feldman \& Pentland, 2003), work routines should be clear in order to permit a good work flow, yet not be too strictly defined. Learning and control over routines increase power, while unpredictable routines are barriers to autonomy and participation, and can institutionalize a poor learning environment and involuntary non-use of ICT for novices.

Although the demand, control, and support model (Karasek \& Theorell, 1990) is a wellestablished operationalization of employees' psychosocial work environment, there have been few attempts to operationalize the dimensions of demands, control, and support further. There is research that strengthens the plausibility of the relationship between learning and identified working conditions, but so far not so much that ties it to the psychosocial work environment. A connection there is likely although this observation is more a theoretical inference based on what is known at this point. Moreover, presenting any phenomenon as a dichotomous dimension is usually a simplification, at best. These working conditions and their interrelationships with power, ICT, employees, and other organizational factors surely contain more facets than just two opposite poles. Simplification is, however, sometimes necessary in order to expose the searched-for phenomena. The nature and expression of these working conditions may also vary depending on the organizational context.

The aspect of external versus internal causes to involuntary non-use can also be questioned here. If power differences inhibit learning, then what are the real barriers toward use - not meeting employee needs of control and support, or the conditions that constitute a poor learning environment? In this respect, it is suitable to look at the chain of causality displayed in Figures 3 and 4. The findings show how differences in power actively shape a succession of interactions, from power differences via who control the organization of work to working conditions that have differential influence on the learning environment of experts and novices. It is ultimately the power differences, with experience as moderator, and the quality of employees' learning environment as a first level outcome that create involuntary non-use as a second-level outcome. Who 'become' the experts and who are assigned the role of novices may vary depending on the workplace in question.

\section{Conclusion}

In the organizations' attempts to explain the novices' underutilization of the new ICT, the challenges the experts eventually faced in the ICT-organization integration processes were attributed to system characteristics, whereas the challenges faced by the novices were attributed largely to personal characteristics. The higher status of the experts allowed them to reorganize work in a way that provided them with a high-quality learning environment as well as the ability to control and monitor novices' work performance. The working conditions that emerged from this reorganization created a poor learning environment for the ICT novices and contributed to maintaining and reinforcing this power imbalance. The ICT novices never got the opportunity to come to terms with the new ICT and experienced involuntary non-use. Prior to the installation of Power Data, there was a variety of other ICT solutions; however, these were single-standing systems, partially overlapping and partially complementary, and had a much lower user threshold than Power Data. The novices' degree of interaction with others in the organization was far higher, which facilitated information and knowledge exchange. There was no ICT training program, but the novices were informally allowed to use a variety of heuristics to bypass or deal with the systems. With the implementation of Power data, ICT use became mandatory, and the workflow was reorganized in a way that isolated and marginalized the novices. The power differences between ICT experts and ICT novices thus increased following the installation of Power Data. The installers remained low in ICT use as they practically were left no proper course of action in dealing with the new ICT. 
This was a comprehensive case study that involved several trained researchers specialized in the field of work and organizations. The study pertained to Guba and Lincoln's (1989) quality criteria for qualitative research, judging the trustworthiness of its method. All activities were performed by at least two researchers. Researcher behaviors were discussed regularly during the project, including ethics, and interview guides were thoroughly worked through. In addition, both methods and findings were continuously discussed with case representatives from all three occupational groups. These formed a reference group that was stable throughout the project. An important criterion is that the method should be fitted to the research problem, which is exemplified in this study with the transition from Phase I to Phase II. The change in focus came as a result of negative case analysis. Unlike positivist standards, in qualitative research, changes are seen as a natural part of the research process, as long as significant criteria are met. The researchers regularly reviewed the theoretical underpinnings of the study in order to identify underlying values, eventual shortcomings, and hidden biases. Prolonged engagement, persistent observation, and peer debriefing was inherent in the execution of the study. Peer debriefing - discussing method and results with a certified colleague - helped assure that the interpretation of results were not colored by the researchers' cognitive representations. The aim of this thoroughness was to strengthen the validity and reliability of the findings. There is, however, always a possibility that the validity of the study and of the findings may be jeopardized by numerous factors. The longterm perspective and the plurality of researchers involved may counteract the limitations and weaknesses of qualitative studies.

The findings yield several possibilities for further research. First, the nature of the political processes is not fully explored in this study, as the main focus has been on power, ICT, and involuntary non-use. Second, the study shows that the differences in power arise between experts and novices. It is therefore not possible to predict the outcome of a situation where the different occupational groups are equally skilled in ICT. Perhaps the latent political processes would be more observable if all employees were at the expert level. Another possible scenario is an organization where all employees are moderately skilled in working with ICT. How could power differences arise, and what would be the critical working conditions for a balance between demands, control, and support that advances learning and ICT use in this context? At this point, it is difficult to say much about the generalizability of these findings.

Likewise, there is a need to know more about how employees' levels of demands, control and support at work affect their learning abilities. The relationship between power (differences) and learning with the demand-control-support model as mediating variables is interesting to explore further. The findings here open for a possible further operationalization of the demand-controlsupport model, or at least a renewed exploration of factors in employees' work situation that further rather than hinder learning and development. The perspectives of sociomateriality and situated change may provide fruitful tools for investigating these matters further.

\section{Implications for Practice}

ICT implementation is complex and can easily fail. This study shows that power differences between groups can cause involuntary non-use of new ICT in organizations. Working conditions central to learning affect the relationship between use and involuntary non-use.

These findings represent constructive contributions for managers facing the introduction of new technology that naturally brings on additional organizational changes. They provide a broader perspective on the non-use of new ICT. Turning involuntary ICT non-use around to ICT use requires different measures than working with resistance behaviors. Involuntary non-use of new ICT stems from an inability to use it. Through a pre-implementation mapping of (1) tasks and their workflow, and (2) competencies, involving the entire organization, managers can get a realistic basis for the beneficial redesign of the organization of work. However, redesigning the or- 
ganization of work may call for a re-identification of work-based identities. During implementation, managers can establish action points, which focus especially on these working conditions. This ensures proper integration of tasks, competences, and working conditions, which is identitybuilding. These findings inform managers on how to design the implementation process, taking care also to embed necessary additional organizational changes. It is important to set aside enough time, and to use the time well. Employees from all organizational settings should be involved in all stages of the implementation processes; for example, in hybrid groups, in order to avoid disadvantageous differences in power.

\section{References}

Alvesson, M. (1993). Organizations as rhetoric: Knowledge-intensive firms and the struggle with ambiguity. Journal of Management studies, 30(6), 997-1015.

Armenakis, A.A., Harris S. G., \& Mossholder, K. W. (1993). Creating readiness for organizational change. Human Relations, 46(6), 681-703.

Baumer, E. P., Burrell, J., Ames, M. G., Brubaker, J. R., \& Dourish, P. (2015). On the importance and implications of studying technology non-use. Interactions, 22(2), 52-56.

Beaudry, A., \& Pinsonneault, A. (2010). The other side of acceptance: Studying the direct and indirect effects of emotions on information technology use. MIS quarterly, 34(4), 689-710.

Benoliel, J. Q. (1996). Grounded theory and nursing knowledge. Qualitative Health Research, 6(3), 40628.

Bisel, R. S., \& Barge, J. K. (2011). Discursive positioning and planned change in organizations. Human Relations, 64(2), 257-83.

Boonstra, J. J., \& Bennebroek Gravenhorst, K. M. (1998). Power dynamics and organizational change: A comparison of perspectives. European Journal of Work and Organizational Psychology, 7(2), 97-120.

Boudreau, M. C., \& Robey, D. (2005). Enacting integrated information technology: A human agency perspective. Organization Science, 16(1), 3-18.

Bourdieu, P. (1996). The state nobility: Elite schools in the field of power (L. C. Clough, Trans.). Stanford, California: Stanford University Press.

Breaugh, J. A. (1989). The work autonomy scales: Additional validity evidence. Human Relations, 42(11), 1033-56.

Brown, J. S. (1998). Internet technology in support of the concept of "communities-of-practice": The case of Xerox. Accounting, Management and Information Technologies, 8(4), 227-236.

Buchanan, D., \& Badham, R. (1999). Politics and organizational change: The lived experience. Human Relations, 52(5), 609-29.

Burton-Jones, A., \& Hubona, G. S. (2006). The mediation of external variables in the technology acceptance model. Information \& Management, 43(6), 706-717.

Charmaz, K. (2000). Constructivist and objectivist grounded theory. In N. K. Denzin \& Y. Lincoln (Eds.), Handbook of qualitative research ( $2^{\text {nd }}$ ed., pp. 509-535). Thousand Oaks, CA: Sage.

Clegg, S. (1989). Frameworks of power. New York: Sage

Constantinides, P., \& Barrett, M. (2006). Large-scale ICT innovation, power, and organizational change. The case of a regional health information network. The Journal of Applied Behavioral Science, 42(1), 76-90.

Corbin, J., \& Strauss, A. (Eds.) (2008). Basics of qualitative research: Techniques and procedures for developing grounded theory. London: Sage. 
Cordery, J. L., Morrison, D., Wright, B. M., \& Wall, T. D. (2010). The impact of autonomy and task uncertainty on team performance: A longitudinal field study. Journal of Organizational Behavior, 31(2-3), $240-58$.

Davidson, E., \& Vaast, E. (2010). Digital entrepreneurship and its sociomaterial enactment. In Proceedings of $43^{\text {rd }}$ Hawaii International Conference on System Sciences (HICSS) (pp. 1-10). DOI:10.1109/HICSS.2010.150

Davis, F. D. (1985). A Technology Acceptance Model for empirically testing new end-user information systems: Theory and results, $\mathrm{PhD}$ thesis. Massachusetts Institute of Technology.

Davis, F. D. (1989). Perceived usefulness, perceived ease of use, and user acceptance of information technology. MIS Quarterly, 13(3), 319-340.

Dawson, P., \& Buchanan, D. (2005). The way it really happened: Competing narratives in the political process of technological change. Human Relations, 58(7), 845-865.

Delbridge, R. (2007). Explaining conflicted collaboration: A critical realist approach to hegemony. Organization Studies, 28(9), 1347-57.

Feldman, M. S., \& Pentland, B. T. (2003). Reconceptualizing organizational routines as a source of flexibility and change. Administrative Science Quarterly, 48(1), 94-118.

Gaver, W. W. (1991, April). Technology affordances. In Proceedings of the SIGCHI conference on Human factors in computing systems (pp. 79-84). ACM.

Giddens, A. (1984). The constitution of society: Outline of the theory of structuration. California: University of California Press.

Glaser, B. \& Holton, J. (2004). Remodeling grounded theory. Grounded Theory Review, 4(1), 1-24.

Guba, E., \& Lincoln, Y. (1989). Fourth generation evaluation. Beverly Hills, CA: Sage.

Hatch, M. J., \& Cunliffe, A. L. (2006). Organization theory: Modern, symbolic and postmodern perspectives. Oxford: Oxford University Press.

Jian, G. (2007). "Omega is a four-letter word": Toward a tension-centered model of resistance to information and communication technologies. Communication Monographs, 74(4), 517-40.

Karasek, R., \& Theorell, T. (1990). Healthy work. Basic Books, New York.

Karasek, R., Brisson, C., Kawakami, N., Houtman, I., Bongers, P., \& Amick, B. (1998). The Job Content Questionnaire (JCQ): An instrument for internationally comparative assessments of psychosocial job characteristics. Journal of Occupational Health Psychology, 3(4), 322-55.

Klev, R., \& Levin, M. (2012). Participative transformation: Learning and development in practicing change. Surrey: Gower Publishing Limited.

Knippenberg, D. V. \& Schie, E. C. M. V. (2000). Foci and correlates of organizational identification. Journal of Occupational and Organizational Psychology, 73, 137-147.

Kuhn, T., \& Corman, S. R. (2003). The emergence of homogeneity and heterogeneity in knowledge structures during a planned organizational change. Communication Monographs, 70(3), 198-229.

Kvale, S. (1996). Interviews. An introduction to qualitative research interviewing. London: Sage.

Lapointe, L., \& Rivard, S. (2005). A multilevel model of resistance to information technology implementation. MIS Quarterly, 29(3), 461-91.

Legris, P., Ingham, J., \& Collerette, P. (2003). Why do people use information technology? A critical review of the Technology Acceptance Model. Information \& Management, 40(3), 191-204.

Leonardi, P. M., \& Bailey, D. E. (2008). Transformational technologies and the creation of new work practices: Making implicit knowledge explicit in task-based offshoring. MIS Quarterly, 32(2), 411-436. 
Majchrzak, A., \& Markus, M. L. (2013). Technology affordances and constraints theory (of MIS). In E. Kessler (Ed.), Encyclopedia of management theory (pp. 832-836). Thousand Oaks, CA: Sage

Markus, M. L., \& Robey, D. (1988). Information technology and organizational change: Causal structure in theory and research. Management Science, 34(5), 583-598.

Martinko, M. J., Gundlach, M. J., \& Douglas, S. C. (2002). Toward an integrative theory of counterproductive workplace behavior: A causal reasoning perspective. International Journal of Selection and Assessment, 10(1-2), 36-50.

McLoughlin, I., \& Badham, R. (2005). Political process perspectives in organization and technological change. Human Relations, 58(7), 827-43.

Mills, D. (1996). The changing social contract in American business. European Management Journal, 14(5), 451-56.

Mizrahi, S. (2002). Workers' participation in decision-making processes and firm stability. British Journal of Industrial Relations, 40(4), 689-707.

Orlikowski, W. J. (1992). The duality of technology: Rethinking the concept of technology in organizations. Organization Science, 3(3), 398-427.

Orlikowski, W. J. (2009). The sociomateriality of organisational life: Considering technology in management research. Cambridge Journal of Economics, 34(1), 125-141.

Pfeffer, J. (1981). Power in organizations (Vol. 33). Marshfield, MA: Pitman.

Reason, P. (1998). Three approaches to participative inquiry. In N. K. Denzin \& Y. S. Lincoln (Eds.), Strategies of qualitative inquiry (pp. 324-39). London: Sage.

Robey, D., \& Boudreau, M. C. (1999). Accounting for the contradictory organizational consequences of information technology: Theoretical directions and methodological implications. Information Systems Research, 10(2), 167-185.

Salancik, G. R., \& Pfeffer, J. (1977). An examination of need-satisfaction models of job attitudes. Administrative Science Quarterly, 22(3), 427-456.

Selwyn, N. (2003). Apart from technology: Understanding people's non-use of information and communication technologies in everyday life. Technology in Society, 25(1), 99-116.

Slater, M. (1986). Non-users in industry and commerce. Management Research News, 9(2), 15-17.

Spector, P. E. (1986). Perceived control by employees: A meta-analysis of studies concerning autonomy and participation at work. Human Relations, 39(11), 1005-1016.

Spicer, A. (2005). The political process of inscribing a new technology. Human Relations, 58(7), 567-90.

Strauss, A., \& Corbin, J. (1998). Basics of qualitative research. Thousand Oaks, CA: Sage.

Suthers, D. D. (2006). Technology affordances for intersubjective meaning making: A research agenda for CSCL. International Journal of Computer-Supported Collaborative Learning, 1(3), 315-337.

Symon, G. (2008). Developing the political perspective on technological change through rhetorical analysis. Management Communication Quarterly, 22(1), 74-98.

Thompson, M. P. (2005). ICT, power and developmental discourse: A critical analysis. The Electronic Journal of Information Systems in Developing Countries, 20.

Trist, E. (1981). The evolution of socio-technical systems. Occasional paper, 2.

Venkatesh, V., \& Davis, F. D. (2000). A theoretical extension of the technology acceptance model: Four longitudinal field studies. Management Science, 46(2), 186-204.

Venkatesh, V., Morris, M. G., Davis, G. B., \& Davis, F. D. (2003). User acceptance of information technology: Toward a unified view. MIS Quarterly, 27(3), 425-78. 
Venkatesh, V., Bala, H., \& Sykes, T. A. (2010). Impacts of information and communication technology implementations on employees' jobs in service organizations in India: A multi-method longitudinal field study. Production and Operations Management, 19(5), 591-613.

Woolgar, S., \& Cooper, G. (1999). Do artefacts have ambivalence? Moses' bridges, Winner's bridges and other urban legends in S\&TS. Social Studies of Science, 29(3), 433-449.

Wyatt, S., Henwood, F., Hart, A., \& Smith, J. (2005). The digital divide, health information and everyday life. New Media \& Society, 7(2), 199-218.

Zuboff, S. (1988). In the age of the smart machine. The future of work and power. New York: Basic Books

\section{Biography}

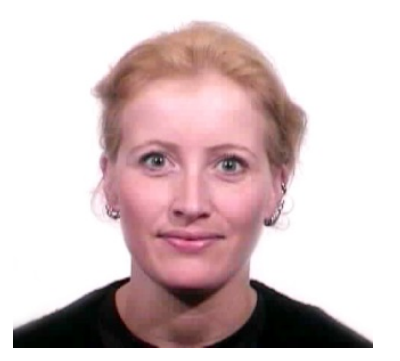

Thale Kvernberg Andersen has been a Research Scientist at SINTEF Technology and Society, in the Department of Industrial Management, for twelve years. She is also affiliated to the Norwegian University of Science and Technology, Department of Industrial Economics and Technology Management, Faculty of Social Sciences and Technology Management, where she is a $\mathrm{PhD}$-candidate on the topic of the integration and use/non-use of new ICT in organizations. Thale Kvernberg Andersen specializes in work- and organizational psychology and in a variety of quantitative and qualitative research methodologies. She has extended experience with research and development work in the fields of management and leadership, organizational change processes, work performance and work practices, involvement and participation, and the interplay between technology, organization, and employees. 